\title{
Ophthalmoscopic signs of obstructed axoplasmic transport after ocular vascular occlusions
}

\author{
DAVID MCLEOD \\ From Moorfields Eye Hospital, London
}

Physiologists have known for many years that subcellular particles and molecules constantly flow within the axon of a nerve cell (axoplasmic transport) (Weiss and Hiscoe, 1948). The progress of enzymemarkers and radioactively-labelled proteins may be traced from the nerve cell body (or perikaryon) towards synaptic terminals - orthograde axoplasmic transport-and also in the reverse directionretrograde axoplasmic flow (Lasek, 1967; Watson, 1968; Hanson, 1973; La Vail and La Vail, 1974). Furthermore, direct observation of the movements of organelles to and fro within axons by Nomarski microscopy (Kirpatrick and Stern, 1973; Cooper and Smith, 1974) shows that orthograde and retrograde axoplasmic flow occur simultaneously, although largely independently.

The energy to sustain axoplasmic transport seems to be generated along the length of an axon, probably by oxidative metabolism (Ochs, 197I; Banks, Mayor, and Mraz, 1973). When an axon is severed axoplasmic transport continues for some time in the proximal axon segment and also in the distal segment isolated from the perikaryon, so enzymes and organelles accumulate in proximal and distal axon terminals owing to the obstruction of orthograde and retrograde axonal transport, respectively (Lubinska, 1964, 1971 ; Banks, Mangnall, and Mayor, 1969). Similarly, when part of an axon is deprived of its blood supply axoplasmic debris accumulates at each end of the ischaemic segment as a result of continuing orthograde or retrograde flow (Fig. I). Thus axoplasmic debris would be expected to accumulate within the retina if ganglioncell axons were interrupted between the perikaryon and the optic disc. This phenomenon has been demonstrated experimentally after axonal disrup-

Address for reprints: David McLeod, FRCS, Moorfields Eye Hospital, City Road, London ECIV 2PD tion by laser coagulation and in relation to areas of focal ischaemia after retinal arteriolar occlusion (McLeod, Marshall, Kohner, and Bird, 1976). The aggregation of mitochondria at the site of axonal interruption causes the dense white swelling of the inner retina in cotton-wool spots and at the edges of retinal infarcts, whereas simple axonal swelling elsewhere within an infarct merely produces grey retinal discoloration (Shakib and Ashton, 1966; McLeod, 1975).

In man, branches of the central retinal artery supply the metabolic requirements of ganglion cells and their proximal axon segments while the posterior ciliary arteries supply the needs of axons at the optic nerve head and, via the cilio-retinal arterioles, within a variable area of peripapillary retina. Thus after occlusion of the major posterior ciliary or central retinal arteries the boundary between normal and ischaemic axon segments is situated either at the optic disc or at the border of the cilio-retinal territories in the retina, and an accumulation of axoplasmic debris might be expected at these sites. This paper describes cases of central retinal and posterior ciliary artery occlusion and the clinical manifestations of obstructed axoplasmic transport.

\section{Central retinal artery occlusion and obstructed retrograde axoplasmic transport}

Central retinal artery occlusion causes ischaemic necrosis of ganglion cells and their proximal axon segments so that axoplasmic transport in the nerve fibre layer of the retina ceases. However, those segments of ganglion-cell axons within the intraocular and orbital portions of the optic nerve generally survive retinal artery occlusion, and retrograde axoplasmic transport continues for the short time before ascending (Wallerian) degenera-

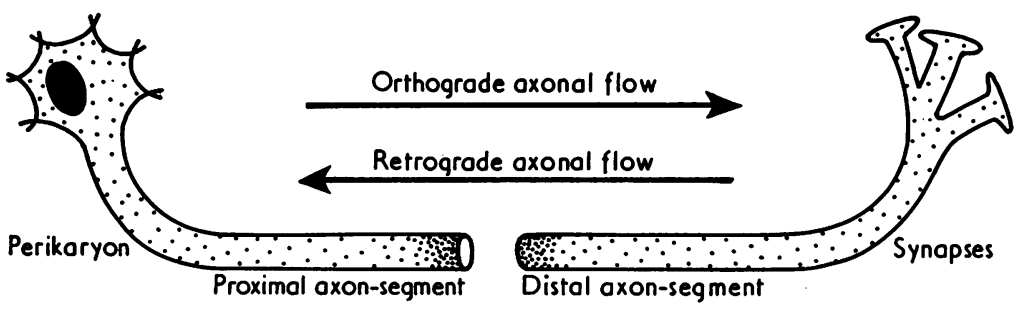

FIG. I Diagram of axoplasmic transport 


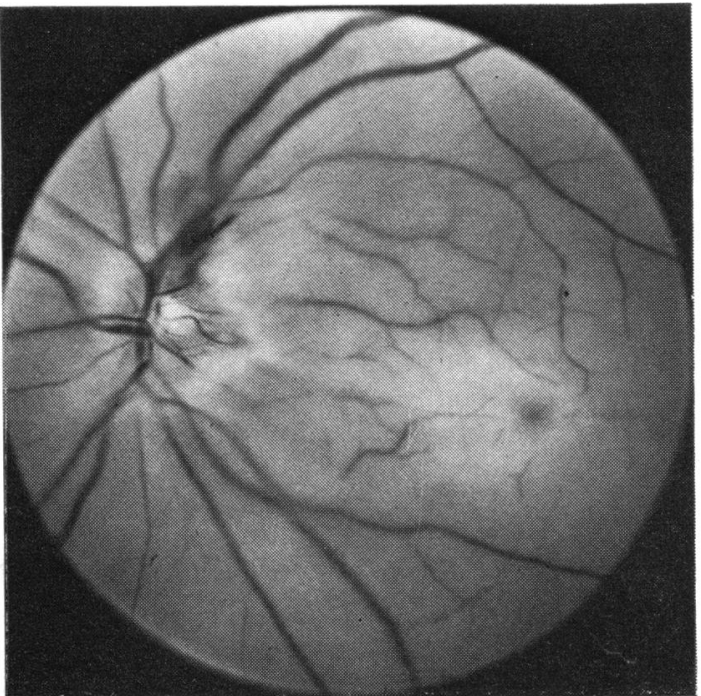

$(2 a)$

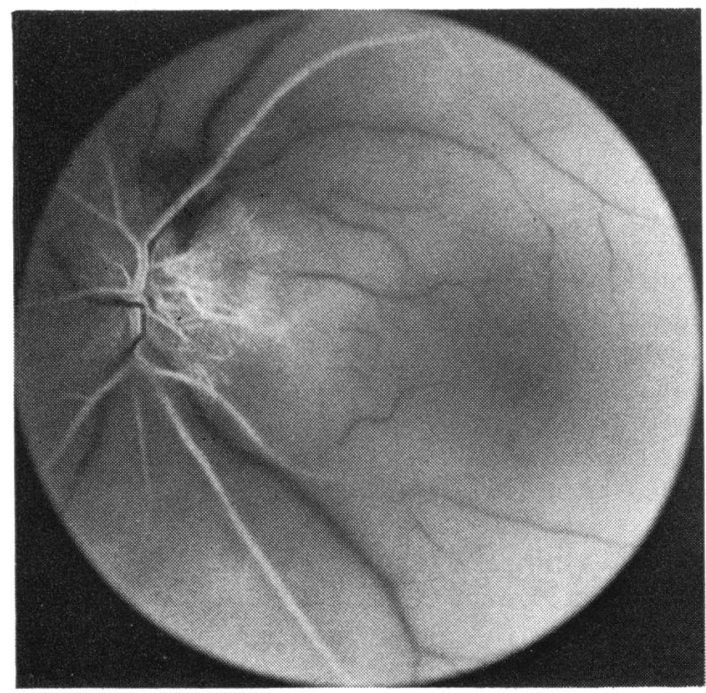

(2b)

FIG. 2 Central retinal artery occlusion three days after visual loss (vision = perception of light). (a) Fundus photograph, disc and macula. (b) Fluorescein angiogram: truncated dye-front in branches of central retinal artery; capillaries of optic nerve head have filled normally

tion starts. Thus axoplasmic debris accumulates in distal axon terminals at the boundary of the ischaemic area.

Fig. 2 illustrates a typical case of central artery obstruction. The juxtapapillary retina showed a localized zone of dense whiteness, as though cottonwool spots were superimposed on retinal cloudy swelling. Fluorescein angiography confirmed that there was minimal perfusion of blood through the central retinal circulation. However, there was no detectable abnormality of the posterior ciliary supply to the optic nerve head, so the boundary between viable and ischaemic axon segments was situated at the edge of the optic disc. Organelles flowing along the optic nerve towards the retina were held up at this site, giving rise to an accumulation of dense white material in the nerve fibre layer.

After occlusion of the central retinal artery in patients who possess a cilio-retinal circulation, the boundary between viable and ischaemic axon segments is displaced from the optic nerve head to the edge of the cilio-retinal arterial territory in the retina. In these circumstances retrograde transport of organelles continues into axon segments beyond the optic disc and axoplasmic debris accumulates near the border of viable peripapillary retina (except where nerve fibres run parallel to this boundary) (Fig. 3).

Alternatively, the site of the boundary of the retinal infarct may be modified by the severity of the central arterial obstruction or the effectiveness of capillary anastomoses between the posterior ciliary and central retinal circulations at the disc. Thus inner retinal elements immediately surrounding major vessels near the disc sometimes survive retinal arterial obstruction (Zimmerman, 1965), and axoplasmic debris can be seen alongside the juxtapapillary vessels in such patients. Similarly, Kroll (r968) illustrated a white sheathing of the peripapillary vasculature which developed within a few hours of central artery obstruction in monkeys.

Hayreh (1965) described an opaque swelling of the optic nerve head after experimental obstruction

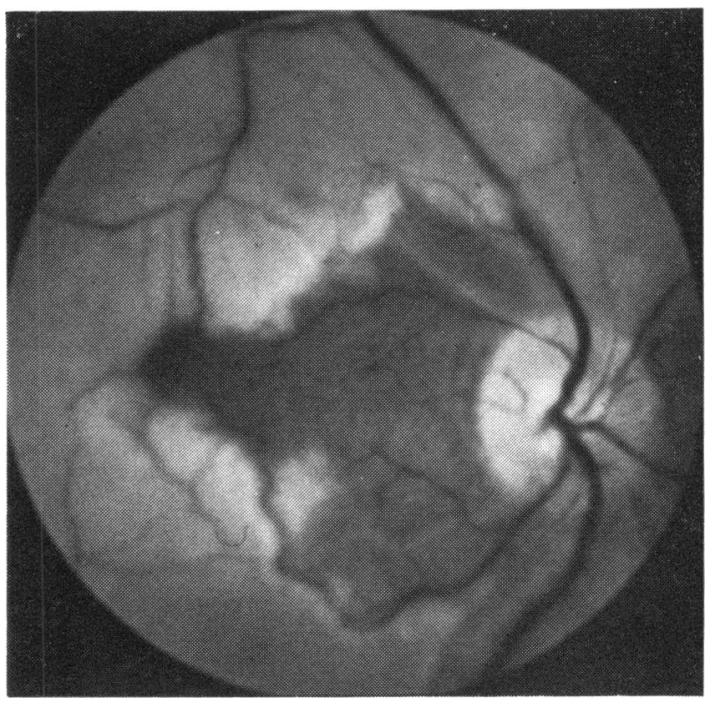

FIG. 3 Central retinal artery occlusion with sparing of cilio-retinal arteriolar territory (vision $=6 / 9$ ) 
of the central retinal artery. However, the accumulation of axoplasmic debris at the optic disc seen clinically in patients with central artery occlusion has often been erroneously interpreted as indicating a combined obstruction of the central retinal and posterior ciliary arteries. In such cases, retinal cloudy swelling may preclude detailed angiographic evaluation of the choroidal circulation, and perfusion of dye through the optic nerve head may appear to be impaired owing to 'masking' by opaque axonal swelling. It is also possible that axonal distension increases the 'tissue pressure' at the optic disc, thus secondarily reducing capillary perfusion.

The absence of a visible accumulation of axoplasmic debris soon after central artery occlusion sometimes indicates that there is an associated occlusion of the posterior ciliary supply to the optic disc (see below); retrograde axoplasmic transport along the optic nerve is obstructed behind the lamina cribrosa in such cases. Alternatively, if the central artery is occluded in the proximal part of its course, a massive accumulation of organelles at the optic nerve head will be prevented in those cases where the central retinal artery provides a major contribution to the blood supply of the orbital portion of the optic nerve. Although the central artery was blocked outside the optic nerve sheath in the experiments of Hayreh (1965) and Kroll (1968), this vessel typically has no intraneural branches in monkeys (Hayreh, 1964; Anderson, 1970), so retrograde axoplasmic transport was obstructed within the eye and not in the orbital part of the optic nerve. The accumulation of axoplasmic debris was therefore visible ophthalmoscopically.

Opaque swelling of nerve fibres usually develops at the edge of the ischaemic area delineated angiographically. However, in some patients central retinal perfusion may improve after organelle aggregation, while in others the posterior ciliary arteries may become obstructed some time after central artery occlusion. Nevertheless, the presence of a peripapillary zone of opaque swelling, as in Fig. 2, clearly indicates that posterior ciliary perfusion was maintained for at least a few hours after central artery occlusion.

\section{Posterior ciliary artery occlusion and obstructed orthograde axoplasmic transport}

Occlusion of the posterior ciliary arteries deprives axons of oxygen and nutrients at the level of the optic nerve head (Foulds, 1969; Hayreh, 1969) but does not prejudice the viability of ganglion cells or of proximal axon segments within the inner retina. Continuing orthograde axoplasmic transport thus results in a massive accumulation of axoplasmic debris at the border of the posterior ciliary territory, causing gross white swelling of the disc (acute

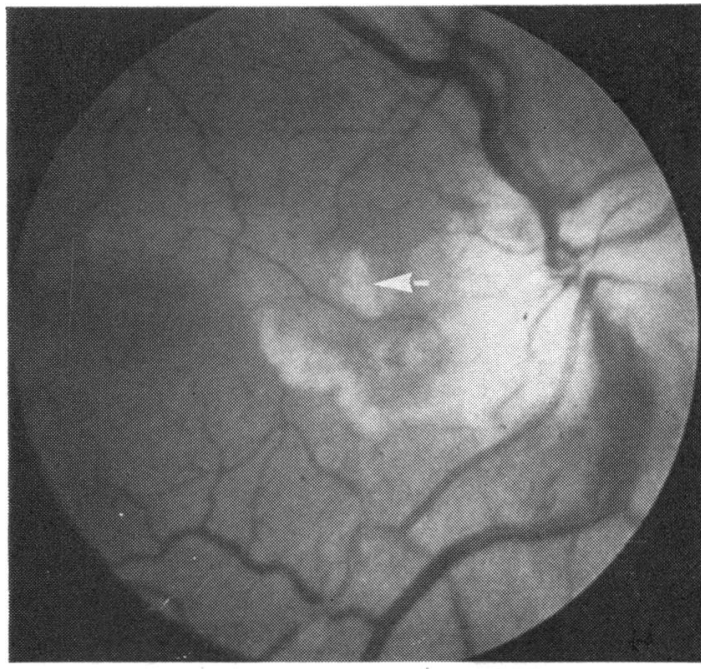

$(4 a)$

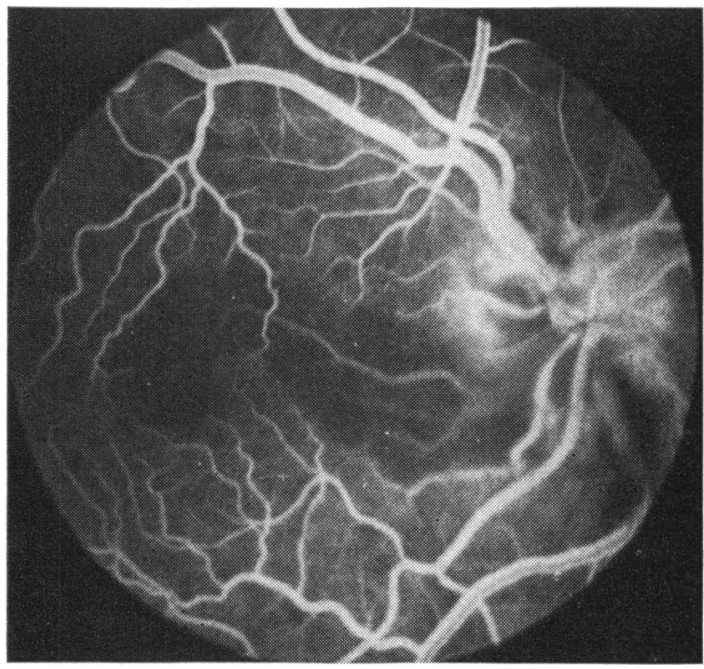

(4b)

FIG. 4 Ischaemic swelling of disc and cilio-retinal arteriolar obstruction due to temporal arteritis four days after visual loss (vision = perception of light). (a) Fundus photograph: Cotton-wool patch arrowed. (b) Fluorescein angiogram: venous phase of central arterial transit; slow filling of cilio-retinal arteriole and temporal part of disc circulation

ischaemic optic neuropathy). In patients with associated infarction of the peripapillary retina due to occlusion of cilio-retinal arterioles orthograde axoplasmic transport in some ganglion-cell axons is obstructed at the border of the infarct rather than at the optic disc, and white debris accumulates in the retina at the boundary between the central retinal and cilio-retinal arterial territories (except where nerve fibres run parallel with this border) (Fig. 4). 
In Fig. $5 a$, from a case of temporal arteritis, grey retinal translucency followed occlusion of an exceptionally large cilio-retinal artery which supplied the superior retinal hemisphere. Fluorescein angiography showed minimal perfusion of dye through the cilio-retinal circulation and the whole of the optic nerve head microcirculation, but opaque disc swelling developed only in the lower half of the optic disc. Indeed, juxtapapillary opacification masked peripapillary chorio-retinal degenerative changes, which were visible through the translucency of nerve fibres from the superior retina. The white swelling of the lower half of the disc represents an accumulation of axoplasmic debris resulting from continuing orthograde axonal flow in the inferior retina. Impaired cilio-retinal perfusion precluded axoplasmic transportation to the optic disc from ganglion cells throughout the superior retinal hemisphere, so no opaque swelling developed in the contiguous sector of the disc at this time. The upper half of the disc later became pale, but not unduly swollen (Fig. $5 b$ ), and no opacity developed at the border between normal and ischaemic retina where this corresponded to the horizontal retinal raphe.

An accumulation of axoplasmic debris at the optic disc has also been observed in some patients with central retinal vein obstruction in whom associated infarction of retina supplied by cilioretinal arterioles provided evidence of impaired posterior ciliary arterial perfusion (McLeod and Ring, 1976). In Fig. 6 venous engorgement and widespread retinal haemorrhages accompanied cloudy swelling of the inner retina in the distribution of two cilio-retinal arterioles. The cilio-retinal territories showed a diffuse grey discoloration, with peripheral white spots where nerve fibres (arising from ganglion cells in the central arterial territory) crossed into ischaemic retina. Where such fibres reached the optic disc without traversing a retinal infarct dense white swelling of the optic nerve head and juxtapapillary retina was seen. However, this feature was absent in those sectors of the disc receiving fibres from areas of contiguous retinal infarction, since organelle transportation could not be sustained within the ischaemic cilio-retinal territories.

Opaque disc-swelling resulting from the aggregation of organelles in a million axons at the optic nerve head may obscure any small disc sector in which few organelles accumulate, as illustrated in Fig. 4a. Furthermore, axonal distension within the rigid confines of the scleral part of the lamina cribrosa and the hiatus in Bruch's membrane may be responsible for exacerbating hypoxic conditions in this region rather than the vicious cycle of ischaemia, increased vascular permeability, and intercellular oedema proposed by Foulds (1969). The concept that ischaemic disc swelling is due to an accumulation of axoplasmic debris accounts for most of the clinical and angiographic features of ischaemic optic neuropathy in temporal arteritis. We have found no evidence to substantiate the suggestion (Hayreh, 1974) that infarction of the peripapillary pigment epithelium contributes to the fundoscopic appearance.

Although signs of obstructed orthograde axoplasmic transport dominate the clinical picture in cases 


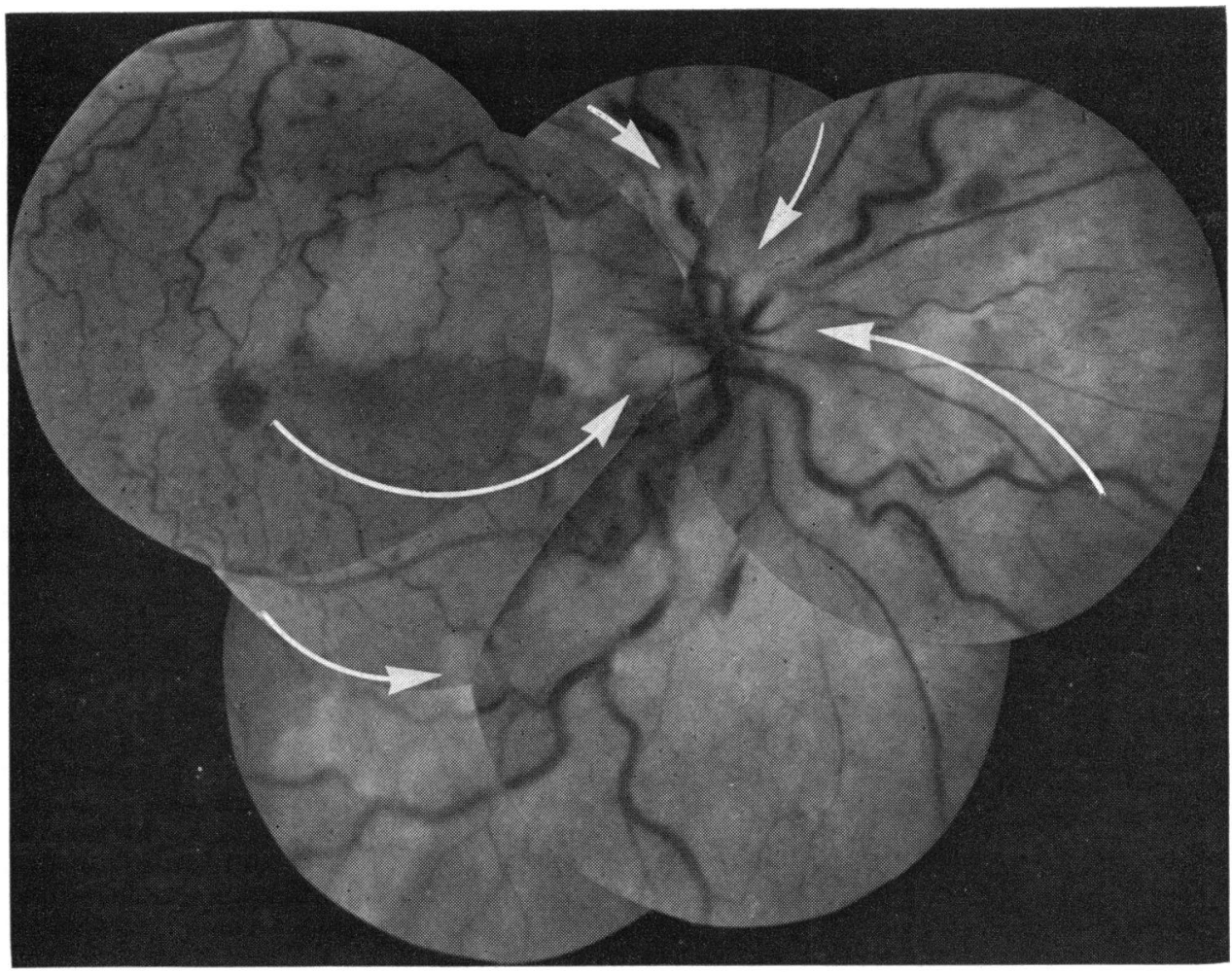

$(6 a)$

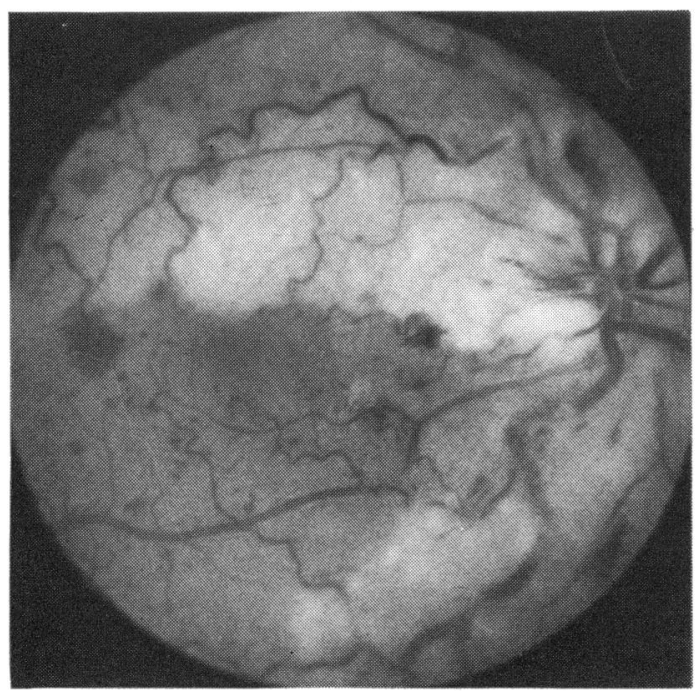

$(6 b)$

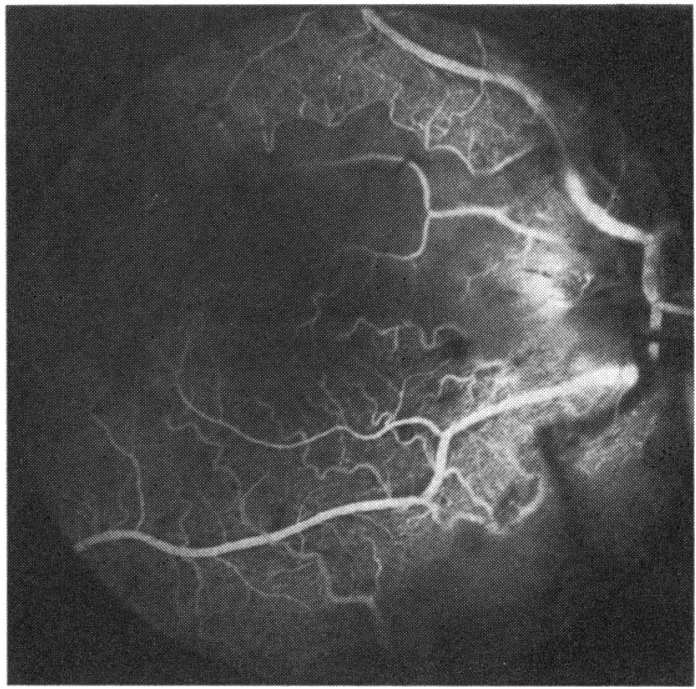

$(6 c)$

FIG. 6 Central retinal vein occlusion, ischaemic swelling of disc, and obstruction of two cilio-retinal arterioles four days after visual loss (vision = finger-counting). (a) Composite fundus photograph, pathway of orthograde axoplasmic transportation arrowed. (b) Detail of (a), disc and macula. (c) Fluorescein angiogram : early venous phase of central arterial transit; slow filling of cilio-retinal arterioles supplying retina below disc and above fovea; no filling of disc capillaries 
of acute ischaemic optic neuropathy, the white debris on the nasal side of the cilio-retinal infarct shown in Fig. 4a (arrowed cotton-wool spot) must reflect obstructed retrograde flow and presumably accumulated early in the evolution of the ischaemic lesion. Furthermore, a retrolaminar aggregation of organelles due to obstructed retrograde axoplasmic transport probably contributes to the welldemarcated zone of retrolaminar degeneration seen pathologically in temporal arteritis (Henkind, Charles, and Pearson, 1970; MacMichael and Cullen, 1972). In keeping with this, Zimmerman, de Venecia, and Hamasaki (1967) found swollen fragmented axons behind the lamina cribrosa in experimental acute glaucoma, and emphasized the resemblance of the optic nerve changes to those observed in retinal cotton-wool spots.

Finally, Miller (1972) postulated that ischaemic disc swelling in temporal arteritis is due to occlusion of the posterior ciliary arteries combined with obstruction of the central retinal artery (which supplies the most superficial layers of the optic nerve head). However, clearly there must be sufficient central arterial perfusion to sustain retinal axoplasmic transport in these cases, since the typical disc appearance depends upon a continuing cellulifugal flow of organelles in the nerve fibre layer of the retina. An analogous situation has been reported by Anderson and Hendrickson (1974), who demonstrated axonal distension, organelle aggregation, and obstructed orthograde axoplasmic transport of radio-leucine at the lamina cribrosa after raising the intraocular pressure in monkeys. No build-up of labelled proteins occurred at very high intraocular pressures, since retinal ischaemia inhibited protein synthesis and prevented axoplasmic transport.

\section{Summary}

When axoplasmic transport in ganglion-cell axons is interrupted by ischaemia organelles accumulate in distended axon terminals at the edges of the infarct. This report illustrates the localized opaque swelling of nerve fibres which develops at or near the optic disc after occlusion of the central retinal or posterior ciliary arteries. No such swelling occurs in patients who have a combined occlusion of these vessels.

I am indebted to $\mathrm{Mr}$ A. C. Bird for advice and encouragement and to Mr R. K. Blach, Dr J. F. Cullen, Professor S. S. Hayreh, Dr E. M. Kohner, and Mr M. D. Sanders for permission to publish details of their patients. Mr K. S. Sehmi produced the illustrations and Mrs M. Nurse and Miss J. Fisher kindly provided secretarial assistance.

\section{References}

ANDERSON, D. R. (1970) Amer. $\mathcal{F . ~ O p h t h a l . , ~ 7 0 , ~ 3 4 I ~}$

, and HENDRICKSON, A. (1974) Invest. Ophthal., 13, 771

Banks, P., Mangnall, D., and Mayor, D. (1969) F. Physiol. (Lond.), 200, 745

-, MAYOR, D., and MRAZ, P. (1973) Ibid., 229, 383

COOPER, P. D., and SMITH, R. I. (1974) Ibid., 242, 77

Foulds, w. S. (1969) Trans. ophthal. Soc. U.K., 89, 125

haNSON, H. A. (1973) Exp. Eye Res., 16, 377

HAYREH, S. S. (1964) Ibid., 3, 16

- (1965) Brit. Y. Ophthal., 49, 626

(1969) Ibid., 53, 721

(1974) Ibid., 58, 964

HENKind, P., Charles, N. C., and PEARSON, J. (1970) Amer. F. Ophthal., 69, 78

KIRPATrICK, J. B., and STERN, L. z. (1973) Arch. Neurol. (Chic.), 28, 308

KROLl, A. J. (1968) Arch. Ophthal. (Chic.), 79, 453

LA VAIL, J. H., and LA VAIL, M. H. (1974) f. comp. Neurol., 157, 303

LASEK, R. J. (1967) Nature (Lond.), 216, 1212

LUBINSKa, L. (1964) Progr. Brain Res., 13, I

(1971) Acta neuropath. (Berl.), Suppl. V, 136

MCLEOD, D. (1975) Lancet, 2, 954

-——, Marshall, J., KoHNER, E. M., and BIRD, A. c. (1976) $\mathcal{~}$. clin. Sci. mol. Med. (in press)

—, and RING, C. P. (1976) Brit. F. Ophthal., 60, 419

MACMiChael, I. M., and CUllen, J. F. (1972) 'Proceedings of and William MacKenzie Symposium on the Optic

Nerve, Glasgow', ed. J. S. Cant, p. ro8. Kimpton, London

MILLER, S. J. H. (1972) Trans. ophthal. Soc. U.K., 92, 563

ochs, s. (1971) Proc. nat. Acad. Sci. (Wash.), 68, 1279

ShaKiв, M., and ASHTON, N. (1966) Brit. F. Ophthal., 50, 325

Watson, w. E. (1968) $\mathcal{F}$. Physiol. (Lond.), r96, 122 P

WEISS, P., and HISCOE, H. B. (1948) F. exp. Zool., ro7, 315

ZIMMERMAN, L. E. (1965) Arch. Ophthal. (Chic.), 73, 822

- - DE VENECIA, G., and HAMASAKI, D. I. (1967) Invest. Ophthal., 6, I०9 